\title{
Tuberculosis Comorbidity with Communicable and Noncommunicable Diseases
}

\author{
Matthew Bates ${ }^{1,2}$, Ben J. Marais ${ }^{3}$, and Alimuddin Zumla ${ }^{4}$ \\ ${ }^{1}$ University of Zambia-University College London Medical School (UNZA-UCLMS) Research \\ and Training Project ${ }^{5}$, University Teaching Hospital, Lusaka RW1X, Zambia \\ ${ }^{2}$ Center for Clinical Microbiology, Department of Infection, Division of Infection and Immunity, University \\ College London, London, United Kingdom \\ ${ }^{3}$ Marie Bashir Institute for Infectious Diseases and Biosecurity (MBI) and The Children's Hospital \\ at Westmead, Sydney Medical School, University of Sydney, Sydney, Australia \\ ${ }^{4}$ National Institute of Health Research, Biomedical Research Centre, Royal Free Campus Rowland Hill St, \\ University College London Hospitals, London NW3 2PF, United Kingdom \\ Correspondence: a.zumla@ucl.ac.uk
}

The 18th WHO Global Tuberculosis Annual Report indicates that there were an estimated 8.6 million incident cases of tuberculosis (TB) in 2012, which included 2.9 million women and 530,000 children. TB caused 1.3 million deaths including 320,000 human immunodeficiency virus (HIV)-infected people; three-quarters of deaths occurred in Africa and Southeast Asia. With one-third of the world's population latently infected with Mycobacterium tuberculosis (Mtb), active TB disease is primarily associated with a break down in immune surveillance. This explains the strong link between active TB disease and other communicable diseases (CDs) or noncommunicable diseases (NCDs) that exert a toll on the immune system. Comorbid NCD risk factors include diabetes, smoking, malnutrition, and chronic lung disease, all of which have increased relentlessly over the past decade in developing countries. The huge overlap between killer infections such as TB, HIV, malaria, and severe viral infections with NCDs, results in a "double burden of disease" in developing countries. The current focus on vertical disease programs fails to recognize comorbidities or to encourage joint management approaches. This review highlights major disease overlaps and discusses the rationale for better integration of tuberculosis care with services for NCDs and other infectious diseases to enhance the overall efficiency of the public health responses.

D uring the past two decades, health priorities in developing countries have been determined primarily by the epidemics of killer infectious diseases, particularly tuberculosis (TB), HIV/AIDS (acquired immunodeficiency

syndrome), and malaria. The 2013 WHO Global TB report estimates that 8.6 million TB cases occurred in 2012, causing 1.3 million deaths of which 320,000 were in HIV-infected people (WHO 2013). Three-quarters of TB deaths oc-

${ }^{5}$ www.unza-uclms.org

Editors: Stefan H.E. Kaufmann, Eric J. Rubin, and Alimuddin Zumla

Additional Perspectives on Tuberculosis available at www.perspectivesinmedicine.org

Copyright (C) 2015 Cold Spring Harbor Laboratory Press; all rights reserved; doi: 10.1101/cshperspect.a017889

Cite this article as Cold Spring Harb Perspect Med 2015;5:a017889 
M. Bates et al.

curred in Africa and Southeast Asia, with South Africa and India accounting for one-third of all deaths. An estimated 3 million people with active TB were either not diagnosed or diagnosed but not reported. Copresentation of severely ill patients with other communicable and noncommunicable diseases (NCDs) is a major cause of TB-associated deaths (Bates et al. 2012; Geneau and Hallen 2012; Remais et al. 2013) (Table 1).

The global burden of NCDs, particularly cancer, cardiovascular disease, diabetes, and chronic respiratory disease, accounts for nearly

Table 1. Key messages

TB comorbidity with noncommunicable diseases (NCDs) and other communicable diseases (CDs) is highly prevalent in TB endemic regions of the world. Population attributable TB risk estimates for diabetes, malnutrition, smoking, excessive alcohol use, and HIV infection are high.

Traditional vertical (disease-specific) approaches to health care services delivery often fail to recognize potential synergies. Wider integration of TB control activities present opportunities to explore commonalities and optimize synergies without sacrificing recent gains or eroding the functionality of existing programs.

The lethal bidirectional interaction between $\mathrm{TB}$ and HIV coinfection in sub-Saharan Africa exemplifies the need for well-integrated approaches to disease management and control.

The looming threat of diabetes mellitus (DM) and TB also calls for bidirectional screening and the need to tackle a broader range of overlapping diseases in resource-poor countries. High levels of TB comorbidity in patients admitted to hospital with CDs or NCDs and in pregnant women attending antenatal clinics are easily overlooked in $\mathrm{TB}$ endemic areas.

Efficient integration of TB services should be encouraged, while maintaining some vertical elements to secure essential functions such as drug supply, monitoring and evaluation, and national surveillance, to a point in which the national TB program may be limited to a small central team providing general oversight. half of all disability and two-thirds of deaths worldwide (Beaglehole et al. 2011; WHO 2011). The prevalence of NCDs is increasing the fastest in low- and middle-income countries and impacting disproportionately on disadvantaged communities. In 2010, more than 2 million deaths attributable to NCDs occurred in sub-Saharan Africa, a 46\% (95\% CI 41-59) increase from 1990 (Lozano et al. 2012). In developing countries, major demographic shifts, urbanization, changing environmental factors, economic empowerment, and accompanying lifestyle changes have led to a rapid increase in NCDs (Lim et al. 2012). Undernutrition, tobacco use, the growing diabetes epidemic, and indoor air pollution are also impacting TB control adversely in Southeast Asian nations. In the sub-Saharan African context, the impact of the HIV epidemic is more significant on TB. So prevention and treatment policy and programming have to take these factors into account.

The convergence of certain NCDs with TB and other communicable diseases now poses concurrent health challenges, which requires a radical shift in emphasis toward multidisciplinary collaboration and integrated strategies. Health services in resource-limited countries are not tailored to deal with this double burden of disease, and thus simple and effective adjustments to health systems are required, which can significantly improve joint care (Adeyi and Robles 2007). In high comorbidity populations, it is critical that health ministries, and nongovernmental intervention and research organizations, appreciate the limitations of vertical approaches focused on individual diseases.

Table 2 illustrates synergies between TB and NCDs that could be explored in public health efforts, such as joint health promotion strategies, reciprocal screening programs, and coordinated treatment. Figure 1 provides absolute and attributable TB risk estimates for diabetes, malnutrition, smoking, excessive alcohol use, and HIV infection. A review of autopsies performed on patients who died with TB in London determined that 35 out of 46 cases had comorbidities, which were primarily hepatitis $\mathrm{C}$ virus and HIV infections, cancer, cardiovas- 
TB and Comorbidities with CDs and NCDs

Table 2. Differences, similarities, and potential synergies between tuberculosis (TB) and noncommunicable diseases (NCDs)

\begin{tabular}{|c|c|}
\hline \multicolumn{2}{|l|}{ Differences and similarities } \\
\hline Tuberculosis & NCDs \\
\hline Transmissible & Not transmissible \\
\hline $\begin{array}{l}\text { Infection control } \\
\text { important }\end{array}$ & $\begin{array}{l}\text { No infection control } \\
\text { issues }\end{array}$ \\
\hline Need to prevent & Need to prevent \\
\hline POC testing problematic & POC testing common \\
\hline Curable & Rarely curable \\
\hline Long-term treatment & $\begin{array}{l}\text { Long-term } \\
\text { management }\end{array}$ \\
\hline Major adherence issues & Major adherence issues \\
\hline Require lifestyle changes & $\begin{array}{l}\text { Require lifestyle } \\
\text { changes }\end{array}$ \\
\hline $\begin{array}{l}\text { Most cases can be managed } \\
\text { at primary HC level }\end{array}$ & $\begin{array}{l}\text { Most cases managed at } \\
\text { primary HC level }\end{array}$ \\
\hline \multicolumn{2}{|l|}{ Potential synergies } \\
\hline \multicolumn{2}{|c|}{$\begin{array}{l}\text { Reciprocal screening for TB, other CDs (malaria, } \\
\text { HIV) and NCDs }\end{array}$} \\
\hline \multicolumn{2}{|c|}{$\begin{array}{l}\text { Combined health messaging and communication } \\
\text { strategies }\end{array}$} \\
\hline \multicolumn{2}{|c|}{$\begin{array}{l}\text { Coordinated human resource development/training } \\
\text { opportunities }\end{array}$} \\
\hline \multicolumn{2}{|c|}{ Combined infrastructure development } \\
\hline \multicolumn{2}{|c|}{ Cross-utilization of health care workers } \\
\hline \multicolumn{2}{|c|}{$\begin{array}{l}\text { Unified point of care; avoids multiple clinic } \\
\text { attendances }\end{array}$} \\
\hline \multicolumn{2}{|c|}{ Integrated recording/reporting systems } \\
\hline \multicolumn{2}{|c|}{$\begin{array}{l}\text { Opportunities for community and user education/ } \\
\text { engagement }\end{array}$} \\
\hline \multicolumn{2}{|c|}{ Poverty alleviation strategies } \\
\hline \multicolumn{2}{|c|}{$\begin{array}{l}\text { Creating an environment that sustains health and } \\
\text { well-being }\end{array}$} \\
\hline
\end{tabular}

cular disease, and chronic obstructive pulmonary disease (COPD) (Sbrana et al. 2011). This review describes the major comorbidities associated with active TB disease, describes key clinical and molecular interactions, and discusses the implications for disease control policy.

\section{TUBERCULOSIS AND NONCOMMUNICABLE DISEASES}

Diabetes

The epidemiological link between diabetes and TB is well established, but during the last half century, populations that have developed high rates of diabetes (wealthier, overnourished, more sedentary working environments) have been distinct from those still dogged by rampant TB (poorer, undernourished, persistence of grueling manual working environments). Increasing industrialization and urbanization in developing countries are leading to growth in rates of diabetes, leading to a potentially cataclysmic confluence of NCDs (of which diabetes is one of the most common) and CDs (of which TB is the most common). In parts of India and China, this has already become a reality, as swathes of the traditionally rural populous flock to overcrowded dwellings in urban centers to take up minimum wage employment in poorly ventilated factories and mines ( $\mathrm{Li}$ et al. 2012; Lin et al. 2012; Viswanathan et al. 2012).

Several large case-controlled and longitudinal cohort studies have shown that the relative odds of developing active TB ranges from two to eight in diabetic patients versus nondiabetic controls (reviewed by Dooley and Chaisson 2009). These studies were in different populations globally, controlling for the particular risk factors, which predominate in each study population. A recent meta-analysis concluded that diabetes patients were $3.1 \times$ more likely to develop active TB than controls, although relative risk was lower in North American study populations (Jeon and Murray 2008). TB is also more likely in insulin-dependent versus non-insulindependent diabetes patients (Olmos et al. 1989; Swai et al. 1990; Leung et al. 2008).

Studies have shown a negative impact of diabetes on treatment outcomes including an up to fourfold increase in the risk of treatment failure (Mboussa et al. 2003; Morsy et al. 2003; Alisjahbana et al. 2007). Studies from Turkey and the United States following up patients for a shorter period suggest that diabetes is linked with modest delays in clearance (Guler et al. 2007; Restrepo et al. 2008), although one Indian study found that whereas diabetes patients were more likely to be smear-positive (which bodes well for diagnosis), they had higher smear conversion rates at 3 mo (Singla et al. 2006). 
M. Bates et al.

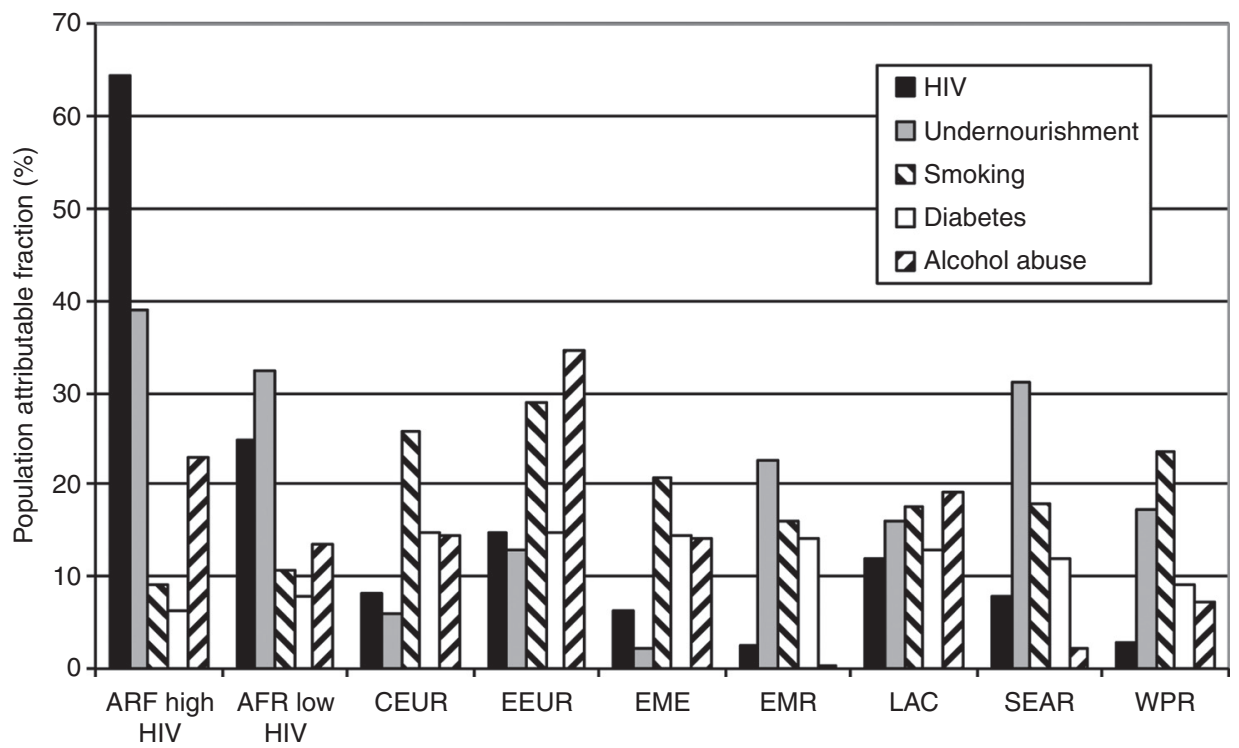

Figure 1. Estimates of population attributable to TB disease risk caused by HIV, undernutrition, smoking, diabetes, and alcohol abuse. AFR high HIV: African countries with high HIV prevalence. AFR low HIV: African countries with low/moderate HIV prevalence. CEUR: Central European countries. EEUR: Eastern European countries. EME: Established market economies. EMR: Eastern Mediterranean region. LAC: Latin American countries. SEAR: Southeast Asian region. WPR: Western Pacific region (except EME). Population attributable fraction $(\mathrm{PAF})=[$ prevalence $\times($ relative risk -1$)] /[$ prevalence $\times($ relative risk -1$)+1]$. Point estimates of relative risk from systematic reviews were used. When prevalence was only available for adults, the prevalence in adults was adjusted for proportion of population under the age of 15 to estimate the total population PAF. HIV (human immunodeficiency virus infection): Relative risk $=27$. Undernourishment (undernutrition): Relative risk $=3.2$ (for BMI 16 vs. BMI 25). Diabetes (DM, diabetes mellitus): Relative risk = 3.1. Alcohol abuse: Relative risk $=2.9$. Prevalence data: Average of prevalence of heavy drinking in China, Brazil, India, Nigeria, Pakistan, Russia, South Africa, and Thailand. Smoking (cigarette smoking): Relative risk $=2.0$ (current vs. never smokers). (Adapted from Lönnroth et al. 2010 and Creswell et al. 2011.)

There are reports for and against an association between diabetes and drug-resistant tuberculosis (Dooley and Chaisson 2009), with possible explanations including delayed clearance resulting in routine switching to a twodrug regimen in patients who are still culturepositive or lowered rifampicin levels in diabetes patients (Nijland et al. 2006). Among TB patients, having diabetes is linked with a significant increase in the risk of death (Dooley et al. 2009; Ismail and Bulgiba 2013). Very little of the available data comes from sub-Saharan African populations, where diabetes prevalence will increase over the next decade (Dooley and Chaisson 2009) and where TB and diabetes treatment decisions for significant numbers of patients will have to frequently accommodate antiretroviral therapy, which itself is associated with increased risk of TB (Marais et al. 2013). Diabetes mellitus (DM) increases the risk of active TB by a factor of 2 to 3 . In addition, people with $\mathrm{TB}$, who have diabetes, have been found to have worse TB treatment outcomes. The WHO and The International Union Against Tuberculosis and Lung Disease Framework for Collaborative Activities recommend screening for $\mathrm{TB}$ and diabetes simultaneously. The recommended collaborative activities, outcome indicators, and research areas for guiding public health policies for joint TB and diabetes care recommend screening for active TB in patients with diabetes and for diabetes in patients with $\mathrm{TB}$ to make 
earlier diagnoses, which in turn may lead to better treatment outcomes and control of both diseases (Table 3) (WHO/IUATBLD 2011]).

\section{Malnutrition}

Malnutrition is a risk factor for all infectious diseases because it impairs immunity. Both protein calorie malnutrition (PCM) and micronutrient deficiencies can cause immune suppression through a variety of mechanisms, as reviewed in Bhaskaram (2002) and Schaible and Kaufmann (2007). Chronic malnutrition has a great impact on chronic infectious diseases such as HIV and TB, which require constant immune surveillance and control. The prevalence of malnutrition, generally defined by a BMI of $<18.5 \mathrm{~kg} / \mathrm{m}^{2}$, among adult pulmonary TB patients can range from $42 \%$ to $80 \%$ (Kennedy et al. 1996; Zachariah et al. 2002; Dodor 2008; Mupere et al. 2012; Bhargava et al. 2013). In the African studies, the prevalence of malnutrition was lower among women, whereas in the Indian study, it was lower among men. These studies did not compare the prevalence of malnutrition among TB patients with that of the general population, but they did look at the effect of malnutrition on TB treatment outcomes. Three of these studies showed improvements in nutritional status with TB treatment, but weight gain did not correlate with microbiological response and significant numbers of patients cured of TB were still underweight at $12 \mathrm{mo}$, indicating the overriding influence of socioeconomic factors (Kennedy et al. 1996; Dodor 2008; Bhargava et al. 2013). A Korean study also found malnutrition to be associated with poorer outcomes in disseminated TB (Kim et al. 2008). One Tanzanian study identified TB as an important correlate of wasting, independent of HIV (Villamor et al. 2006), and Malawian, Ugandan, and Indian studies found that severe malnutrition on admission was independently linked with increased risk of early mortality (Zachariah et al. 2002; Mupere et al. 2012; Bhargava et al. 2013). A Latvian study found that being underweight was linked with worse outcomes and increased mortality in multidrug-resistant (MDR)-TB (Podewils et al. 2011).
Children primarily acquire active TB from adults with whom they live, and so one would expect the prevalence of malnutrition among children with $\mathrm{TB}$ to be similar if not higher than among adult TB patients, with households affected by malnutrition more likely to suffer transmission events from infected adults to children. A study from Pakistan found 51\% of children initiating TB therapy to have PCM (Uddin Siddiqui et al. 2010), and there is a need for more research to evaluate possible interventions to cotreat malnutrition and tuberculosis and to assess to what degree nutritional interventions might be able to prevent the development of active TB in high-risk children (Jaganath and Mupere 2012).

\section{TUBERCULOSIS AND OTHER COMMUNICABLE DISEASES}

\section{HIV/AIDS}

In the early 1990s, researchers started to ask questions about the effect of HIV coinfection on TB prevalence, drug reactions, and treatment outcomes. A U.S. study of prisoners was the first paper in which the term "coinfection" was used with respect to HIV and TB (Salive et al. 1990). Subsequent studies in various patient groups showed significantly higher prevalence of HIV-1 infection in TB patients (Singh et al. 1993; Greenberg et al. 1994; Kivihya-Ndugga et al. 1994a), including children (Chintu et al. 1993), showing associations with more severe disease (Kivihya-Ndugga et al. 1994a), more advanced immune suppression (Kivihya-Ndugga et al. 1994b; Martin et al. 1995), and drug reactions (Pozniak et al. 1992).

In the subsequent two decades, the HIV epidemic has expanded dramatically in some countries, dragging both pulmonary and extrapulmonary TB in its wake, fueling a fivefold increase in TB notification rates between 1990 and 2010 in sub-Saharan Africa, which bears $80 \%$ of the global HIV disease burden. HIV increases TB risk by 20 - to 40 -fold and TB accounts for $25 \%$ of HIV-related deaths worldwide - the single largest cause. The WHO Global Tuberculosis Report 2013 states that 13\% 
M. Bates et al.

Table 3. Recommended collaborative activities, outcome indicators, and research areas for guiding public health policies for joint TB and diabetes care

\begin{tabular}{ll}
\hline Area & Recommendation \\
\hline A. Establish mechanisms for collaboration
\end{tabular}

\section{A. Establish mechanisms for collaboration}

A.1. Setup means of coordinating diabetes and TB Recommendation 1: Joint coordination should be activities

A.2. Conduct surveillance of TB disease prevalence among people with diabetes in medium and high TB burden settings

A.3. Conduct surveillance of diabetes prevalence in TB patients in all countries

A.4. Conduct monitoring and evaluation of collaborative diabetes and TB activities

\section{B. Detect and manage TB in patients with diabetes}

B.1. Intensify detection of $\mathrm{TB}$ among people with diabetes

B.2. Ensure TB infection control in health-care settings where diabetes is managed

B.3. Ensure high-quality TB treatment and management in people with diabetes established at regional, district, and/or local levels (sensitive to country-specific factors), with representation from all relevant stakeholders. A joint plan for diabetes and TB activities should be drawn up and reflected in national plans on noncommunicable diseases and $\mathrm{TB}$, respectively.

Recommendation 2: There should be TB surveillance among diabetes patients in settings with medium to high TB burden.

Recommendation 3: There should be surveillance of diabetes among TB patients in all countries.

Recommendation 4: Where diabetes and TB collaboration is being established, programs for both diseases should agree on a core set of indicators and data collection tools for the monitoring and evaluation of collaborative activities. Diabetes programs should explore the possibility of adapting the directly observed therapy (DOT) system to monitor and report cases and treatment outcomes.

Recommendation 5: At a minimum, people with diabetes should be asked about the presence of cough (lasting $>2 \mathrm{wk}$ ) at the time of diabetes diagnosis, and if possible at each regular check-up for diabetes. Those with positive symptoms should be examined as per national guidelines. Other diagnostic procedures, such as those for extrapulmonary TB, should be pursued rigorously as per national guidelines.

Recommendation 6: Screening for active TB on broader indications (e.g., in all people diagnosed with diabetes, regardless of symptoms) should be explored as part of the research agenda for improved TB diagnosis among people with diabetes.

Recommendation 7: A referral system should be established so that patients with suspected TB are promptly sent to TB diagnostic and treatment centers and evaluated in accordance with the guidelines of the national TB control program.

Recommendation 8: Tuberculosis case finding should be intensified by increasing the awareness and knowledge of the interactions between diabetes and TB, including joint risk factors, among health-care workers and populations they serve.

Recommendation 9: Each health-care facility, including diabetes clinics, should have an infection control plan (including a plan for TB infection control), which includes administrative and environmental control 
TB and Comorbidities with CDs and NCDs

Table 3. Continued

\begin{tabular}{ll}
\hline Area & \multicolumn{1}{c}{ Recommendation } \\
\hline & measures to reduce transmission of TB within this \\
setting. These measures should adhere to WHO's & International guidelines for TB infection control. \\
Recommendation 10: Treatment and case management of & TB in people with diabetes should be provided in \\
& accordance with existing TB treatment guidelines and \\
& international standards. The same TB treatment \\
& regimen should be prescribed to people with diabetes \\
& as for people without diabetes.
\end{tabular}

C. Detect and manage diabetes in patients with $T B$ C.1. Screen TB patients for diabetes

C.2. Ensure high-quality diabetes management among TB patients
D. Key processes, outcome indicators, and research questions

Recommendation 11: TB patients should be screened for diabetes at the start of treatment. Type of screening and diagnostic tests should be adapted to the context of local health systems and the availability of resources, while awaiting additional evidence on the best screening and diagnostic approach.

Recommendation 12: Management of diabetes in TB patients should be provided in line with existing guidelines.

1. Joint $\mathrm{TB}$ and diabetes plan in place

2. Number and proportion of people with diagnosed diabetes who have been screened for chronic cough

3. Number and proportion of people with diabetes who have been tested for TB (radiography, sputum smear microscopy, culture, Xpert MTB/Rif Assay, etc.)

4. Prevalence of TB among people with diabetes

5. Number and proportion of people with TB who have been screened for diabetes

6. Prevalence of diabetes among people with TB

7. TB treatment outcomes among people with diabetes

Data adapted from WHO/IUATBLD 2011.

(1.1 million) of 8.6 million people who developed TB in 2012 are coinfected with HIV (WHO 2013). With respect to HIV/TB, the report highlights some modest improvementscoverage of ART (antiviral therapy) and cotrimoxazole preventative therapy have improved among HIV-positive TB patients in recent years. Isoniazid preventive therapy (IPT) was provided to one-third of all new HIV cases diagnosed in 2012 , although $50 \%$ are likely eligible. It remains unclear how appropriate this is in extremely high-burden settings.

As one of five key priority areas, the report highlights the need for improved coverage of dual HIV/TB testing, which in some countries approaches $100 \%$, indicating what is possible. Low HIV burden countries have had more problems, or shown less initiative, in promoting HIV counseling and testing among newly diagnosed TB patients. In the Africa region, the epicenter of the HIV pandemic, up to $77 \%$ of TB patients are coinfected with HIV, and the rate of TB patients who have undergone HIV testing has increased dramatically in recent years. Seven highburden countries, mainly from Eastern and Southern Africa, have HIV testing rates in TB clinics higher than $90 \%$, lead by Zambia, the only country to test virtually all notified $\mathrm{TB}$ 
M. Bates et al.

cases for HIV. Because HIV status may inform on treatment decisions in comorbid patients (e.g., toxicities and pharmacokinetic interactions of TB and ARTor other drugs), Diagnostic Counseling and Testing (DCT) or "opt out" strategies have been instigated in some in-patient settings and high-risk groups. In recent years, WHO has invested in improved data collection systems for TB/HIV; however, in many countries, there is still a great need for improved data collection, with data from both HIV and TB programs irreconcilable in some cases. There are also still significant patient groups that go under the radar and are not captured. For example, data from Zambia shows that TB is frequently missed in a range of hospitalized patients, attributable to overriding symptoms indicative of one or more comorbid communicable or noncommunicable diseases (Bates et al. 2012). Those who are discharged should be referred back to their community TB treatment center, but there are no funds to follow up such cases, and the large number of missed TB patients who die shortly after admission are not reported to the National Tuberculosis Programmes (NTPs). Most importantly, rates of MDR-TB within this high morbidity and mortality, HIV-positive inpatient group may approach $10 \%$, resulting in possible gross underestimation of MDR-TB cases in what are currently considered to be relatively low MDR-TB prevalence countries (Bates et al. 2012).

The treatment of HIV and TB in coinfected patients is potentially complicated by toxicities and pharmacokinetic interactions between the drugs used in anti-TB and ART, but because of the considerable number of drugs available, regimens can often be adjusted to reduce side effects and nonadherence (Arentz et al. 2012). HIV-infected TB patients initiated on ART benefit from increased survival and cure rates, whether on first-line (Gengiah et al. 2011) or second-line anti-TB therapy (Arentz et al. 2012). WHO recommend that ART should be commenced as soon as possible after initiating TB treatment, especially in patients with CD4 counts of $<50$ cells $/ \mathrm{mL}$, but early mortality remains a significant problem in patients initiating ART and trials are under way to evaluate the possible benefits of presumptive TB treatment in high-risk patients with very low CD4 counts (Zumla et al. 2013).

In sub-Saharan Africa, TB now supersedes obstetric causes of death in HIV-infected pregnant women, with vertical transmission of $\mathrm{TB}$ occurring in up to $15 \%$ of neonates born to mothers suffering from $\mathrm{HIV} / \mathrm{TB}$ coinfection (Adhikari et al. 2011; Bekker et al. 2012). With $\mathrm{HIV}$-infected persons living longer on ART (Volberding and Deeks 2010; Ullrich et al. 2011), and the huge success of interventions to reduce mother-to-child-transmission (MTCT) of HIV (Sturt et al. 2010), the number of children born to HIV/TB coinfected mothers is set to increase and so is the burden of neonatal TB. There is a need for more research into possible ways to prevent MTCT of TB and on how best to diagnose and treat TB in the HIV-exposed neonate, which compounds just about all diagnostic and treatment challenges seen in other patient groups.

\section{Malaria}

Although there is considerable literature on $\mathrm{HIV} /$ tuberculosis and HIV/malaria coinfections and comorbidity, there has been distinctly less attention given to both clinical and immunological interactions between TB and malaria. Unlike HIV, both Mycobacterium tuberculosis $(\mathrm{Mtb})$ and Plasmodium species are ancient pathogens that have coevolved in the same human populations over millennia, with molecular evidence for coinfections shown in 2000-3000-yr-old mummified remains from lower Egypt (Lalremruata et al. 2013). When two chronic pathogens have coevolved in the same population, it is possible (if not highly likely) that they have evolved mutually beneficial "win-win" strategies, to aid their own persistence and transmission. Could there be molecular synergies between plasmodium and $M t b$ that contribute to each other's persistence in endemic regions (Enwere et al. 1999)?

Animal model studies suggest infection with malaria induces immune responses that impair host resistance to chronic TB infection, with 
TB and Comorbidities with CDs and NCDs

exacerbated leukocyte infiltrates, tissue pathology, and hypercytokinemia accompanied by altered T-cell responses, pointing to malaria-induced dysregulation of innate and adaptive antimycobacterial defenses (Hawkes et al. 2010; Mueller et al. 2012). Other animal model studies have shown that coinfected mice were less able to inhibit $M t b$ growth in lungs, spleen, and liver (Scott et al. 2004) and that TB and malaria trigger similar innate immune responses such as the heme oxygenase 1 pathway, enhancing the efficiency of the liver stage in the Plasmodium life cycle (Sinnis and Ernst 2008). Conversely, it is also possible that under certain circumstances, coinfecting pathogens may possess competitive strategies, with one study showing $M t b$-induced protective effects against lethal murine malaria (Page et al. 2005). Another study showed that murine malaria infection did not have any effect on vaccine-induced TB immunity (Parra et al. 2011).

There are few studies that document crosssectional prevalence of malaria in TB patients, with rates ranging from $5 \%$ to $37 \%$, because of differences in study location, population, and definitions used (Range et al. 2007; Valadas et al. 2013). Malaria infection can inhibit TB interferon- $\gamma$ release assays (IGRAS) (Banfield et al. 2012), but this is mute, in that these diagnostics are not generally recommended for use in high-burden populations. There are also some potential drug interactions that should be considered when treating coinfected patients. Fluoroquinalones are contraindicated with other drugs that prolong ventricular repolarization, recorded as lengthening of the QT interval on an electrocardiogram (Murphy et al. 2012). Induction of the hepatic cytochrome P450 enzyme system by rifampicin results in a halving in the serum concentrations of artemisinin and its derivatives, complicating the concurrent management of TB and acute malaria. There is a case report in the literature of malaria and TB coinfection presenting as sepsis in a neonate (Thapa et al. 2010). This is of potential impact in that blood cultures from neonates with suspected sepsis are often negative, with testing for nonbacterial infections such as malaria and TB often overlooked.

\section{Influenza}

Data from the 1918 influenza epidemic suggested a clear association with increased risk for TB-related disease and death during this time period. Mouse models have shown that prior exposure to influenza A impairs immune responses to $M t b$ infection and decreases survival (Redford et al. 2014), possibly through down-regulated MHC (major histocompatibility complex) expression on dendritic cells and reduced activation of CD4 and CD8 T cells to clear mycobacteria (Florido et al. 2013). A similar murine study found influenza had little effect on mycobacterial load (Co et al. 2006). Clinical data from Southeast Asia does not support an association between influenza and TB (de Paus et al. 2013; Noh et al. 2013; Roth et al. 2013). Even studies from high HIV burden patient groups in South Africa have found TB coinfection in the $2009 \mathrm{H} 1 \mathrm{~N} 1$ outbreak to be rare in influenza deaths (10\%), with pregnancy being a more potent risk factor (Archer et al. 2009).

Other acute respiratory tract infections are also likely to increase patients' vulnerability to develop $M t b$ infection or disease, and may partially explain some of the seasonal variability observed in temperate regions. A randomized controlled trial to assess the impact of pneumococcal vaccination showed decreased rates of culture-confirmed and clinically diagnosed TB in vaccinated children (Moore et al. 2010). Case ascertainment bias could not be excluded, because unvaccinated children had more frequent respiratory illness warranting diagnostic workup, but it offers the intriguing possibility that pneumococcal coinfection may increase children's vulnerability to develop active TB.

\section{Helminths}

There is increasing recognition that a high exposure to pathogens in poor communities living in tropical and subtropical regions results in immunological profiles with different responses to TB infection (Black et al. 2002). A U.S. study of refugees from TB-endemic countries (free of any acute illness or recent treatment history) 
M. Bates et al.

showed that among those latently infected with TB, those with concurrent helminth or Helicobacter pylori infections had raised levels of IFN- $\gamma$ and other cytokines. H. pylori was associated with enhanced IFN- $\gamma$ responses to TB (Perry et al. 2013). A recent review concluded that there is now strong evidence that helminth-induced T-cell responses impair defenses against $M t b$ infection, with consequences not only for disease prevalence and severity in different regions, but also with respect to TB vaccine efficacy (Rafi et al. 2012). However, there is murine data showing TB vaccine responses are unaffected by helminth-induced Th2 responses (Frantz et al. 2010) and that helminth infection does not exacerbate TB disease (Hubner et al. 2012). Another rodent model showed that prior helminth infections appear to illicit a macro- phage response, which is protective during the early stages of mycobacterial infection (du Plessis et al. 2013).

Human studies in high- and low-burden helminth infection populations found no differences in tuberculin skin test responses in patients with and without helminth infections, or after treatment with albendazole (Pelly et al. 2005; Zevallos et al. 2010). Looking in more detail at components of the immune response, there is evidence for helminth-associated regulatory $\mathrm{T}$ cells suppressing responses to BCG (Bacillus Calmette-Guérin) vaccination in children (Wammes et al. 2010) and Mtb-specific Toll-like receptor expression in adults (Babu et al. 2009). Ex vivo studies in which monocytes differentiated into dendritic cells and macrophages, and then stimulated in vitro with live

Table 4. Social determinants and clinically observed associations with the development of tuberculosis

\begin{tabular}{ll}
\hline Social determinants & Clinically observed associations \\
Living conditions & Other communicable diseases \\
Poverty & HIV/AIDS \\
Crowded accommodation with poor & Sexually transmitted infections \\
ventilation (e.g., prisons, refugee camps, & Infections linked to injection drug use \\
homeless shelters, mass gatherings, shanty & Acute lung infections (viral, bacterial, fungal) \\
towns) & Chronic helminth infestations \\
Under/malnutrition (including & Noncommunicable diseases \\
micronutrient deficiencies) & Diabetes mellitus \\
Poor health services & Chronic lung disease (e.g., COPD, pneumoconiosis) \\
Alcohol or substance misuse & Chronic kidney disease or end stage renal failure \\
Cigarette smoking (active or passive) & Gut malabsorption or gastric bypass surgery \\
Indoor biomass fuel smoke exposure & Skin disorders (e.g., psoriasis, alopecia areata) \\
Birth or residence in TB endemic country & Sarcoidosis \\
Visit to or regular close contact with people & Congenital and other immunodeficiencies \\
from TB endemic countries & Autoimmune diseases \\
High-risk work or living environment & Solid organ transplants \\
Mine workers & Cancers \\
Health care workers & Immunosuppressive therapy \\
Laboratory personnel & Steroids (e.g., prednisone, methylprednisolone) \\
Residential care staff & Antimetabolites (e.g., methotrexate, azathioprine) \\
Inpatients in hospitals & T-cell inhibitors (e.g., cyclosporin, tacrolimus) \\
Prisoners and prison staff & Alkylating agents (e.g., cyclophosphamide) \\
Refugee camp workers & Biologicals (e.g., anti-TNF- $\alpha$ drugs, IL-2 blockers) \\
Homeless & Pregnancy and childbirth \\
Migrants and nomads & Extremes of age \\
& Elderly \\
& Very young \\
\hline & \\
& \\
&
\end{tabular}


TB and Comorbidities with CDs and NCDs

Table 5. Priorities for integration of tuberculosis care with that of other communicable and noncommunicable diseases (CDs and NCDs)

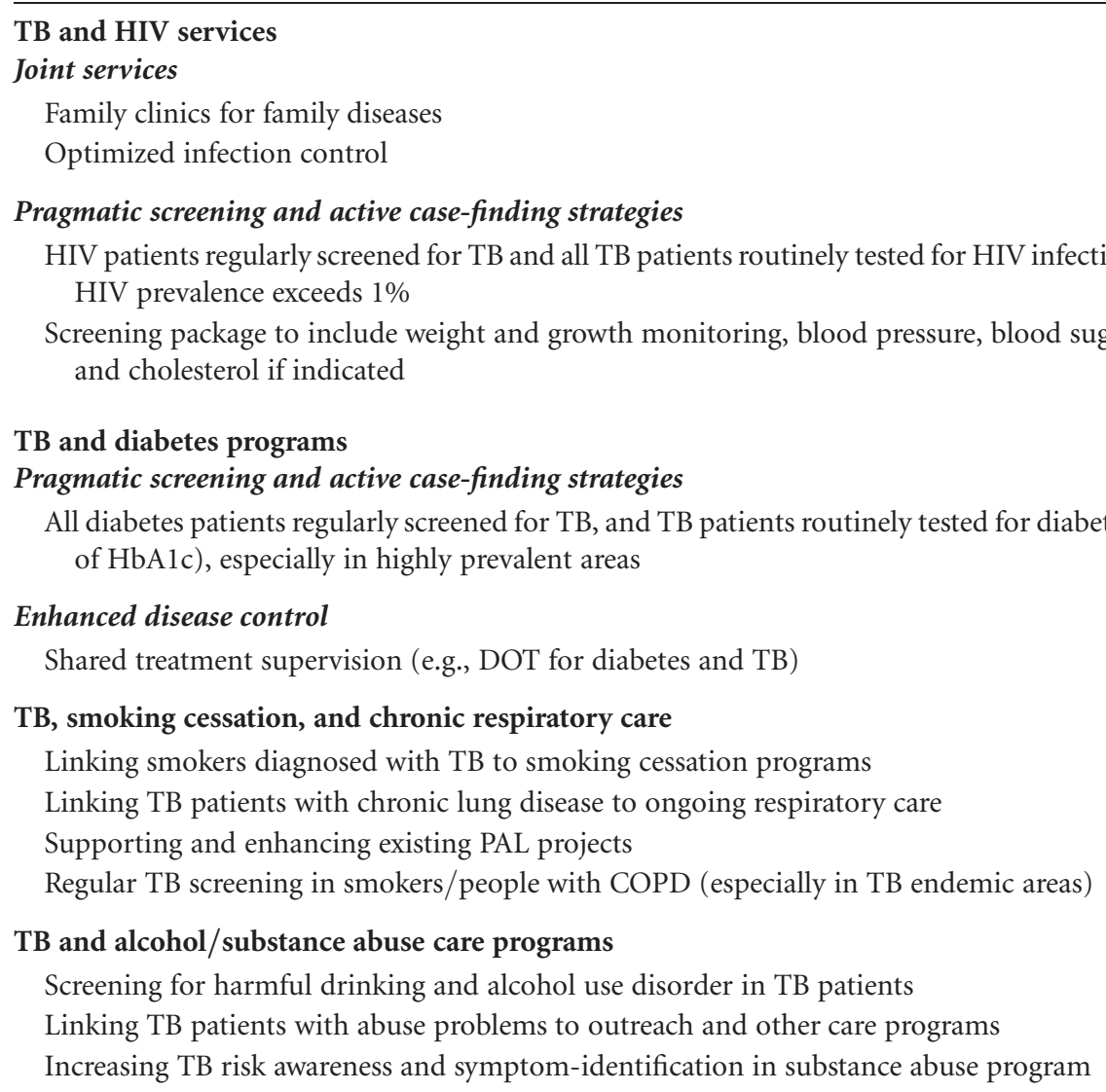

\author{
Maternal and child health initiatives and services \\ Antenatal and obstetric services \\ Routine screening for HIV, TB, malaria (in endemic areas), DM, and hypertension \\ Routine STD screening \\ Administration of BCG vaccination to newborns
}

\title{
Child health
}

Routine administration of expanded EPI with hepatitus B, Haemophilus influenza type B, pneumococcal, rotavirus, and HPV vaccines

Regular monitoring and mapping of weight gain on a "Road to Health chart"

Inclusion of pediatric TB in integrated management of childhood illness (IMCI) approaches

Regular deworming

\section{Public health and advocacy campaigns}

Reduce poverty and deprivation

Promote healthy living

Reduce cigarette smoking (tobacco control), solid fuel use

Reduce excessive alcohol use/substance abuse

Improve health literacy

Modified and adapted from Marais et al. 2013, with permission. 
M. Bates et al.

microfilariae, resulted in cytokine and chemokine expression that would impair the immune response (Talaat et al. 2006). But do these cell responses translate to poorer clinical outcomes? One large well-controlled trial found that treatment of helminths did not affect vaccine responses in Ugandan children (Webb et al. 2011).

\section{NEED FOR INTEGRATED STRATEGIES}

With diminishing investment in global health, integrated solutions should seek to unlock latent synergies and optimize resource utilization. It is particularly important to encourage local ownership and increase equitable domestic investment in health and sustainable development. Rates of TB provide a useful barometer as an "indicator disease" of socioeconomic inequality and deprivation (see Table 4). However, meeting the social and medical care needs of vulnerable communities requires a cohesive response from multiple role players. Within the emerging post-2015 development framework, it is essential to emphasize the strong link between health and responsible development, with $\mathrm{TB}$ providing a classic example of two-way causality. Governments need to develop national health strategic plans that integrate surveillance, diagnostic, and treatment systems to meet the challenges posed by current CD and NCD epidemics including new epidemics and drug-resistant infections. Priorities for integration and alignment of TB care with that of other communicable and noncommunicable diseases (CDs and NCDs) are listed in Table 5. Wider integration of TB control activities presents opportunities to explore latent synergies and getting convergence for achieving universal health care within programs.

\section{ACKNOWLEDGMENTS}

Support from the European Commission FW7 Rid-RTI Project; European and Developing Countries Clinical Trials Partnership, The Hague, Netherlands (EDCTP grants REMOX, PANACEA, and TB-NEAT); UBS Optimus Foundation, Switzerland; NIHR Biomedical Research Centre, University College London
Hospital, London, UK; and Australian NHMRC and the Centre for Research Excellence in Tuberculosis. We are grateful to Mr. Adam Zumla for technical and search strategy support and to Dr. Knut Lonroth, Global TB Department, WHO, Geneva for providing data and Figure 1.

\section{REFERENCES}

Adeyi OSO, Robles S. 2007. Public policy and the challenge of chronic noncommunicable diseases. World Bank, Washington, DC.

Adhikari M, Jeena P, Bobat R, Archary M, Naidoo K, Coutsoudis A, Singh R, Nair N. 2011. HIV-associated tuberculosis in the newborn and young infant. Int J Pediatr 2011: 354208.

Alisjahbana B, Sahiratmadja E, Nelwan EJ, Purwa AM, Ahmad Y, Ottenhoff TH, Nelwan RH, Parwati I, van der Meer JW, van Crevel R. 2007. The effect of type 2 diabetes mellitus on the presentation and treatment response of pulmonary tuberculosis. Clin Infect Dis 45: 428-435.

Archer B, Cohen C, Naidoo D, Thomas J, Makunga C, Blumberg L, Venter M, Timothy G, Puren A, McAnerney $\mathrm{J}$, et al. 2009. Interim report on pandemic H1N1 influenza virus infections in South Africa, April to October 2009: Epidemiology and factors associated with fatal cases. Euro Surveill 14: 19369

Arentz M, Pavlinac P, Kimerling ME, Horne DJ, Falzon D, Schunemann HJ, Royce S, Dheda K, Walson JL, group ARTs. 2012. Use of anti-retroviral therapy in tuberculosis patients on second-line anti-TB regimens: A systematic review. PloS ONE 7: e47370.

Babu S, Bhat SQ, Kumar NP, Anuradha R, Kumaran P, Gopi PG, Kolappan C, Kumaraswami V, Nutman TB. 2009. Attenuation of toll-like receptor expression and function in latent tuberculosis by coexistent filarial infection with restoration following antifilarial chemotherapy. PLoS Negl Trop Dis 3: e489.

Banfield S, Pascoe E, Thambiran A, Siafarikas A, Burgner D. 2012. Factors associated with the performance of a blood-based interferon- $\gamma$ release assay in diagnosing tuberculosis. PloS ONE 7: e38556.

Bates M, O’Grady J, Mwaba P, Chilukutu L, Mzyece J, Cheelo B, Chilufya M, Mukonda L, Mumba M, Tembo J, et al. 2012. Evaluation of the burden of unsuspected pulmonary tuberculosis and co-morbidity with non-communicable diseases in sputum producing adult inpatients. PloS ONE 7: e40774.

Beaglehole R, Bonita R, Alleyne G, Horton R, Li L, Lincoln P, Mbanya JC, McKee M, Moodie R, Nishtar S, et al. 2011. UN high-level meeting on non-communicable diseases: Addressing four questions. Lancet 378: 449-455.

Bekker A, Du Preez K, Schaaf HS, Cotton MF, Hesseling AC. 2012. High tuberculosis exposure among neonates in a high tuberculosis and human immunodeficiency virus burden setting. Int J Tuberc Lung Dis 16: 1040-1046.

Bhargava A, Chatterjee M, Jain Y, Chatterjee B, Kataria A, Bhargava M, Kataria R, D'Souza R, Jain R, Benedetti A, et al. 2013. Nutritional status of adult patients with pulmo- 
TB and Comorbidities with CDs and NCDs

nary tuberculosis in rural central India and its association with mortality. PloS ONE 8: e77979.

Bhaskaram P. 2002. Micronutrient malnutrition, infection, and immunity: An overview. Nutr Rev 60: S40-S45.

Black GF, Weir RE, Floyd S, Bliss L, Warndorff DK, Crampin AC, Ngwira B, Sichali L, Nazareth B, Blackwell JM, et al. 2002. BCG-induced increase in interferon- $\gamma$ response to mycobacterial antigens and efficacy of BCG vaccination in Malawi and the UK: Two randomised controlled studies. Lancet 359: 1393-1401.

Chintu C, Bhat G, Luo C, Raviglione M, Diwan V, Dupont HL, Zumla A. 1993. Seroprevalence of human immunodeficiency virus type 1 infection in Zambian children with tuberculosis. Pediatr Infect Dis J 12: 499-504.

Co DO, Hogan LH, Karman J, Heninger E, Vang S, Wells K, Kawaoka Y, Sandor M. 2006. Interactions between T cells responding to concurrent mycobacterial and influenza infections. J Immunol 177: 8456-8465.

Creswell J, Raviglione M, Ottmani S, Migliori GB, Uplekar M, Blanc L, Sotgiu G, Lönnroth K. 2011. Tuberculosis and non-communicable diseases: Neglected links and missed opportunities. Eur Respir J 37: 1269-1282.

de Paus RA, van Crevel R, van Beek R, Sahiratmadja E, Alisjahbana B, Marzuki S, Rimmelzwaan GF, van Dissel JT, Ottenhoff TH, van de Vosse E. 2013. The influence of influenza virus infections on the development of tuberculosis. Tuberculosis 93: 338-342.

Dodor E. 2008. Evaluation of nutritional status of new tuberculosis patients at the Effia-Nkwanta Regional hospital. Ghana Med J 42: 22-28.

Dooley KE, Chaisson RE. 2009. Tuberculosis and diabetes mellitus: Convergence of two epidemics. Lancet Infect Dis 9: 737-746.

Dooley KE, Tang T, Golub JE, Dorman SE, Cronin W. 2009. Impact of diabetes mellitus on treatment outcomes of patients with active tuberculosis. Am J Trop Med Hyg 80: 634-639.

du Plessis N, Kleynhans L, Thiart L, van Helden PD, Brombacher F, Horsnell WG, Walzl G. 2013. Acute helminth infection enhances early macrophage mediated control of mycobacterial infection. Mucosal Immunol 6: 931-941.

Enwere GC, Ota MO, Obaro SK. 1999. The host response in malaria and depression of defence against tuberculosis. Ann Trop Med Parasitol 93: 669-678.

Florido M, Grima MA, Gillis CM, Xia Y, Turner SJ, Triccas JA, Stambas J, Britton WJ. 2013. Influenza A virus infection impairs mycobacteria-specific $\mathrm{T}$ cell responses and mycobacterial clearance in the lung during pulmonary coinfection. J Immunol 191: 302-311.

Frantz FG, Rosada RS, Peres-Buzalaf C, Perusso FR, Rodrigues V, Ramos SG, Kunkel SL, Silva CL, Faccioli LH. 2010. Helminth coinfection does not affect therapeutic effect of a DNAvaccine in mice harboring tuberculosis. PLoS Negl Trop Dis 4: e700.

Geneau R, Hallen G. 2012. Toward a systemic research agenda for addressing the joint epidemics of HIV/AIDS and noncommunicable diseases. AIDS 31: S7-S10.

Gengiah TN, Gray AL, Naidoo K, Karim QA. 2011. Initiating antiretrovirals during tuberculosis treatment: A drug safety review. Expert Opin Drug Saf 10: 559-574.
Greenberg BL, Weisfuse IB, Makki H, Adler J, el-Sadr W, Clarke L, Gainey S, Alford T, McFarlane K, Thomas PA. 1994. HIV-1 seroprevalence in chest clinic and hospital tuberculosis patients in New York City, 1989-1991. AIDS 8: 957-962.

Guler M, Unsal E, Dursun B, Aydln O, Capan N. 2007. Factors influencing sputum smear and culture conversion time among patients with new case pulmonary tuberculosis. Int J Clin Pract 61: 231-235.

Hawkes M, Li X, Crockett M, Diassiti A, Liles WC, Liu J, Kain KC. 2010. Malaria exacerbates experimental mycobacterial infection in vitro and in vivo. Microbes Infect 12: 864-874.

Hubner MP, Killoran KE, Rajnik M, Wilson S, Yim KC, Torrero MN, Morris CP, Nikonenko B, Blanco JC, Hemming VG, et al. 2012. Chronic helminth infection does not exacerbate Mycobacterium tuberculosis infection. PLoS Negl Trop Dis 6: e1970.

Ismail I, Bulgiba A. 2013. Predictors of death during tuberculosis treatment in TB/HIV co-infected patients in Malaysia. PloS ONE 8: e73250.

Jaganath D, Mupere E. 2012. Childhood tuberculosis and malnutrition. J Infect Dis 206: 1809-1815.

Jeon CY, Murray MB. 2008. Diabetes mellitus increases the risk of active tuberculosis: A systematic review of $13 \mathrm{ob}-$ servational studies. PLoS Med 5: e152.

Kennedy N, Ramsay A, Uiso L, Gutmann J, Ngowi FI, Gillespie SH. 1996. Nutritional status and weight gain in patients with pulmonary tuberculosis in Tanzania. Trans R Soc Trop Med Hyg 90: 162-166.

Kim DK, Kim HJ, Kwon SY, Yoon HI, Lee CT, Kim YW, Chung HS, Han SK, Shim YS, Lee JH. 2008. Nutritional deficit as a negative prognostic factor in patients with miliary tuberculosis. Eur Respir J 32: 1031-1036.

Kivihya-Ndugga LE, Ochola JJ, Otieno G, Muthami LN, Gathua S. 1994a. Clinical and immunological markers in Kenyan pulmonary tuberculosis patients with and without HIV-1. East Afr Med J 71: 373-375.

Kivihya-Ndugga LE, Otieno G, Muthami LN, Gachihi G, Gathua S. 1994b. Markers in HIV associated tuberculosis in Kenya. Afr J Health Sci 1: 122-125.

Lalremruata A, Ball M, Bianucci R, Welte B, Nerlich AG, Kun JF, Pusch CM. 2013. Molecular identification of falciparum malaria and human tuberculosis co-infections in mummies from the Fayum depression (Lower Egypt). PloS ONE 8: e60307.

Leung CC, Lam TH, Chan WM, Yew WW, Ho KS, Leung GM, Law WS, Tam CM, Chan CK, Chang KC. 2008. Diabetic control and risk of tuberculosis: A cohort study. Am J Epidemiol 167: 1486-1494.

Li L, Lin Y, Mi F, Tan S, Liang B, Guo C, Shi L, Liu L, Gong F, Li Y, et al. 2012. Screening of patients with tuberculosis for diabetes mellitus in China. Trop Med Int Health 17: 1294-1301.

Lim SS, Vos T, Flaxman AD, Danaei G, Shibuya K, AdairRohani H, Amann M, Anderson HR, Andrews KG, Aryee $\mathrm{M}$, et al. 2012. A comparative risk assessment of burden of disease and injury attributable to 67 risk factors and risk factor clusters in 21 regions, 1990-2010: A systematic analysis for the Global Burden of Disease Study 2010. Lancet 380: 2224-2260. 
M. Bates et al.

Lin Y, Li L, Mi F, Du J, Dong Y, Li Z, Qi W, Zhao X, Cui Y, Hou F, et al. 2012. Screening patients with diabetes mellitus for tuberculosis in China. Trop Med Int Health 17: $1302-1308$.

Lönnroth K, Castro K, Chakaya JM, Chauhan LS, Floyd K, Glaziou P, Raviglione M. 2010. Tuberculosis control and elimination 2010-50: Cure, care, and social development. Lancet 375: 1814-1829.

Lozano R, Naghavi M, Foreman K, Lim S, Shibuya K, Aboyans V, Abraham J, Adair T, Aggarwal R, Ahn SY, et al. 2012. Global and regional mortality from 235 causes of death for 20 age groups in 1990 and 2010: A systematic analysis for the Global Burden of Disease Study 2010 Lancet 380: 2095-2128.

Marais BJ, Lonnroth K, Lawn SD, Migliori GB, Mwaba P, Glaziou P, Bates M, Colagiuri R, Zijenah L, Swaminathan S, et al. 2013. Tuberculosis comorbidity with communicable and non-communicable diseases: Integrating health services and control efforts. Lancet Infect Dis $\mathbf{1 3}$ 436-448.

Martin DJ, Sim JG, Sole GJ, Rymer L, Shalekoff S, van Niekerk AB, Becker P, Weilbach CN, Iwanik J, Keddy K, et al. 1995. CD4 ${ }^{+}$lymphocyte count in African patients coinfected with HIV and tuberculosis. J Acquir Immune Defic Syndr Hum Retrovirol 8: 386-391.

Mboussa J, Monabeka H, Kombo M, Yokolo D, Yoka-Mbio A, Yala F. 2003. Rev Pneumol Clin 59: 39-44. [Course of pulmonary tuberculosis in diabetics.]

Moore DP, Klugman KP, Madhi SA. 2010. Role of Streptococcus pneumoniae in hospitalization for acute community-acquired pneumonia associated with culture-confirmed Mycobacterium tuberculosis in children: A pneumococcal conjugate vaccine probe study. Pediatr Infect Dis J 29: 1004-1099.

Morsy AM, Zaher HH, Hassan MH, Shouman A. 2003. Predictors of treatment failure among tuberculosis patients under DOTS strategy in Egypt. East Mediter Health J 9: 689-701.

Mueller AK, Behrends J, Hagens K, Mahlo J, Schaible UE, Schneider BE. 2012. Natural transmission of Plasmodium berghei exacerbates chronic tuberculosis in an experimental co-infection model. PloS ONE 7: e48110.

Mupere E, Malone L, Zalwango S, Chiunda A, Okwera A, Parraga I, Stein CM, Tisch DJ, Mugerwa R, Boom WH, et al. 2012. Lean tissue mass wasting is associated with increased risk of mortality among women with pulmonary tuberculosis in urban Uganda. Ann Epidemiol 22: 466473.

Murphy ME, Singh KP, Laurenzi M, Brown M, Gillespie SH. 2012. Managing malaria in tuberculosis patients on fluoroquinolone-containing regimens: Assessing the risk of QT prolongation. Int J Tuberc Lung Dis 16: 144-149, i-iii.

Nijland HM, Ruslami R, Stalenhoef JE, Nelwan EJ, Alisjahbana B, Nelwan RH, van der Ven AJ, Danusantoso $\mathrm{H}$, Aarnoutse RE, van Crevel R. 2006. Exposure to rifampicin is strongly reduced in patients with tuberculosis and type 2 diabetes. Clin Infect Dis 43: 848-854.

Noh JY, Lee J, Choi WS, Song JY, Seo YB, Kim IS, Cheong HJ, Kim WJ. 2013. Concurrent tuberculosis and influenza, South Korea. Emerg Infect Dis 19: 165-167.

Olmos P, Donoso J, Rojas N, Landeros P, Schurmann R, Retamal G, Meza M, Martinez C. 1989. [Tuberculosis and diabetes mellitus: A longitudinal-retrospective study in a teaching hospital.] Rev Med Chil 117: 979-983.

Page KR, Jedlicka AE, Fakheri B, Noland GS, Kesavan AK, Scott AL, Kumar N, Manabe YC. 2005. Mycobacteriuminduced potentiation of type 1 immune responses and protection against malaria are host specific. Infect Immun 73: 8369-8380.

Parra M, Derrick SC, Yang A, Tian J, Kolibab K, Oakley M, Perera LP, Jacobs WR, Kumar S, Morris SL. 2011. Malaria infections do not compromise vaccine-induced immunity against tuberculosis in mice. PloS ONE 6: e28164.

Pelly TF, Santillan CF, Gilman RH, Cabrera LZ, Garcia E, Vidal C, Zimic MJ, Moore DA, Evans CA. 2005. Tuberculosis skin testing, anergy and protein malnutrition in Peru. Int J Tuberc Lung Dis 9: 977-984.

Perry S, Chang AH, Sanchez L, Yang S, Haggerty TD, Parsonnet J. 2013. The immune response to tuberculosis infection in the setting of Helicobacter pylori and helminth infections. Epidemiol Infect 141: 1232-1243.

Podewils LJ, Holtz T, Riekstina V, Skripconoka V, Zarovska E, Kirvelaite G, Kreigere E, Leimane V. 2011. Impact of malnutrition on clinical presentation, clinical course, and mortality in MDR-TB patients. Epidemiol Infect 139: $113-120$

Pozniak AL, MacLeod GA, Mahari M, Legg W, Weinberg J. 1992. The influence of HIV status on single and multiple drug reactions to antituberculous therapy in Africa. AIDS 6: $809-814$.

Rafi W, Ribeiro-Rodrigues R, Ellner JJ, Salgame P. 2012. Coinfection-helminthes and tuberculosis. Curr Opin HIVAIDS 7: 239-244.

Range N, Magnussen P, Mugomela A, Malenganisho W, Changalucha J, Temu MM, Mngara J, Krarup H, Friis H, Andersen AB. 2007. HIV and parasitic co-infections in tuberculosis patients: A cross-sectional study in Mwanza, Tanzania. Ann Trop Med Parasitol 101: $343-$ 351.

Redford PS, Mayer-Barber KD, McNab FW, Stavropoulos E, Wack A, Sher A, O'Garra A. 2014. Influenza A virus impairs control of Mycobacterium tuberculosis coinfection through a type I interferon receptor-dependent pathway. $J$ Infect Dis 15: 270-274

Remais JV, Zeng G, Li G, Tian L, Engelgau MM. 2013. Convergence of non-communicable and infectious diseases in low- and middle-income countries. Int J Epidemiol 42: 221-227.

Restrepo BI, Fisher-Hoch SP, Smith B, Jeon S, Rahbar MH, McCormick JB, Nuevo Santander Tuberculosis T. 2008. Mycobacterial clearance from sputum is delayed during the first phase of treatment in patients with diabetes. $A m$ J Trop Med Hyg 79: 541-544.

Roth S, Whitehead S, Thamthitiwat S, Chittaganpitch M, Maloney SA, Baggett HC, Olsen SJ. 2013. Concurrent influenza virus infection and tuberculosis in patients hospitalized with respiratory illness in Thailand. Influen$z a$ Other Respir Viruses 7: 244-248.

Salive ME, Vlahov D, Brewer TF. 1990. Coinfection with tuberculosis and HIV-1 in male prison inmates. Public Health Rep 105: 307-310.

Sbrana E, Grise J, Stout C, Aronson J. 2011. Co-morbidities associated with tuberculosis in an autopsy case series. Tuberculosis 91: S38-S42. 
Schaible UE, Kaufmann SH. 2007. Malnutrition and infection: Complex mechanisms and global impacts. PLoS Med 4: e115.

Scott CP, Kumar N, Bishai WR, Manabe YC. 2004. Short report: Modulation of Mycobacterium tuberculosis infection by Plasmodium in the murine model. Am J Trop Med Hyg 70: 144-148.

Singh NB, Singh EK, Singh HL, Singh YI. 1993. Tuberculosis/HIV co-infection in India's north-eastern states. $J$ Infect 26: 344-345.

Singla R, Khan N, Al-Sharif N, Ai-Sayegh MO, Shaikh MA Osman MM. 2006. Influence of diabetes on manifestations and treatment outcome of pulmonary TB patients. Int J Tuberc Lung Dis 10: 74-79.

Sinnis P, Ernst JD. 2008. CO-opting the host HO-1 pathway in tuberculosis and malaria. Cell Host Microbe 3: 277-279.

Sturt AS, Dokubo EK, Sint TT. 2010. Antiretroviral therapy (ART) for treating HIV infection in ART-eligible pregnant women. Cochrane Database Syst Rev: CD008440.

Swai AB, McLarty DG, Mugusi F. 1990. Tuberculosis in diabetic patients in Tanzania. Trop Doct 20: 147-150.

Talaat KR, Bonawitz RE, Domenech P, Nutman TB. 2006. Preexposure to live Brugia malayi microfilariae alters the innate response of human dendritic cells to Mycobacterium tuberculosis. J Infect Dis 193: 196-204.

Thapa R, Mallick D, Biswas B. 2010. Perinatal malaria and tuberculosis co-infection: A case report. Int J Infect Dis 14: e254-256.

Uddin Siddiqui E, Ejaz K, Lone S, Raza SJ. 2010. Investment in paediatric tuberculosis prevention in Pakistan: Loss or gain? J Pak Med Assoc 60: 897-901.

Ullrich A, Ott JJ, Vitoria M, Martin-Moreno JM, Atun R. 2011. Long-term care of AIDS and non-communicable diseases. Lancet 377: 639-640.

Valadas E, Gomes A, Sutre A, Brilha S, Wete A, Hanscheid T, Antunes F. 2013. Tuberculosis with malaria or HIV co-infection in a large hospital in Luanda, Angola. J Infect Dev Ctries 7: 269-272.

Villamor E, Saathoff E, Mugusi F, Bosch RJ, Urassa W, Fawzi WW. 2006. Wasting and body composition of adults with pulmonary tuberculosis in relation to HIV-1 coinfection, socioeconomic status, and severity of tuberculosis. Eur J Clin Nutr 60: 163-171.
TB and Comorbidities with CDs and NCDs

Viswanathan V, Kumpatla S, Aravindalochanan V, Rajan R, Chinnasamy C, Srinivasan R, Selvam JM, Kapur A. 2012. Prevalence of diabetes and pre-diabetes and associated risk factors among tuberculosis patients in India. PloS ONE 7: e41367.

Volberding PA, Deeks SG. 2010. Antiretroviral therapy and management of HIV infection. Lancet 376: 49-62.

Wammes LJ, Hamid F, Wiria AE, de Gier B, Sartono E, Maizels RM, Luty AJ, Fillie Y, Brice GT, Supali T, et al. 2010. Regulatory T cells in human geohelminth infection suppress immune responses to BCG and Plasmodium falciparum. Eur J Immunol 40: 437-442.

Webb EL, Mawa PA, Ndibazza J, Kizito D, Namatovu A, Kyosiimire-Lugemwa J, Nanteza B, Nampijja M, Muhangi L, Woodburn PW, et al. 2011. Effect of singledose anthelmintic treatment during pregnancy on an infant's response to immunisation and on susceptibility to infectious diseases in infancy: A randomised, doubleblind, placebo-controlled trial. Lancet 377: 52-62.

WHO. 2011. Burden: Mortality, morbidity and risk factors. In Global status report on noncommunicable diseases 2010 (ed. WHO). WHO, Geneva.

WHO. 2013. Global tuberculosis report 2013. 306. WHO Library Cataloging-in-Publication Data, Geneva, Switzerland.

WHO/IUATBLD. 2011. Collaborative framework for acre and control of tuberculosis and diabetes. WHO/HTM/ 2011.15. International Union Against Tuberculosis and Lung Disease 1-53. http://whqlibdoc.who.int/publica tions/2011/9789241502252_eng.pdf.

Zachariah R, Spielmann MP, Harries AD, Salaniponi FM. 2002. Moderate to severe malnutrition in patients with tuberculosis is a risk factor associated with early death. Trans R Soc Trop Med Hyg 96: 291-294.

Zevallos K, Vergara KC, Vergara A, Vidal C, Garcia HH, Evans CA. 2010. Tuberculin skin-test reactions are unaffected by the severity of hyperendemic intestinal helminth infections and co-infections. Am J Trop Med Hyg 83: 319-325.

Zumla A, Nahid P, Cole ST. 2013. Advances in the development of new tuberculosis drugs and treatment regimens. Nat Rev Drug Discov 12: 388-404. 


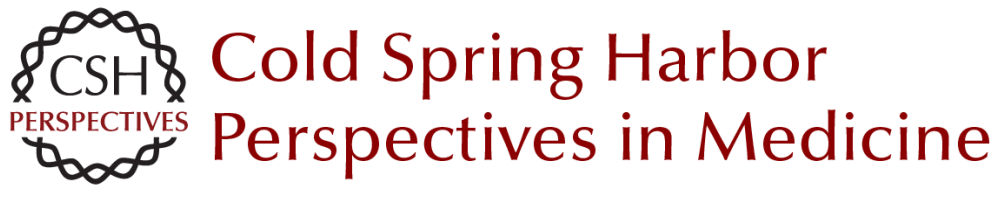

\section{Tuberculosis Comorbidity with Communicable and Noncommunicable Diseases}

Matthew Bates, Ben J. Marais and Alimuddin Zumla

Cold Spring Harb Perspect Med 2015; doi: 10.1101/cshperspect.a017889 originally published online February 6, 2015

Subject Collection Tuberculosis

Transmission and Institutional Infection Control

of Tuberculosis

Edward A. Nardell

Innate and Adaptive Cellular Immune Responses

to Mycobacterium tuberculosis Infection

Katrin D. Mayer-Barber and Daniel L. Barber

Tuberculosis Comorbidity with Communicable and Noncommunicable Diseases

Matthew Bates, Ben J. Marais and Alimuddin Zumla

Host-Directed Therapies for Tuberculosis

David M. Tobin

Immunity and Immunopathology in the

Tuberculous Granuloma

Antonio J. Pagán and Lalita Ramakrishnan

Tuberculosis Drug Development: History and Evolution of the Mechanism-Based Paradigm? Sumit Chakraborty and Kyu Y. Rhee

\section{Genetic Approaches to Facilitate Antibacterial \\ Drug Development \\ Dirk Schnappinger}

The Tuberculosis Drug Discovery and

Development Pipeline and Emerging Drug Targets

Khisimuzi Mdluli, Takushi Kaneko and Anna Upton
Clinical Aspects of Adult Tuberculosis

Robert Loddenkemper, Marc Lipman and Alimuddin Zumla

Advances in Diagnostic Assays for Tuberculosis Stephen D. Lawn

Diagnosis and Management of Latent

Tuberculosis Infection

Laura Muñoz, Helen R. Stagg and Ibrahim Abubakar

Mycobacterial Growth

Iria Uhía, Kerstin J. Williams, Vahid Shahrezaei, et al.

Multidrug-Resistant Tuberculosis and Extensively

Drug-Resistant Tuberculosis

Kwonjune J. Seung, Salmaan Keshavjee and Michael L. Rich

The Mycobacterial Cell Wall--Peptidoglycan and

Arabinogalactan

Luke J. Alderwick, James Harrison, Georgina S. Lloyd, et al.

Tuberculosis and HIV Coinfection Judith Bruchfeld, Margarida Correia-Neves and Gunilla Källenius

Imaging in Tuberculosis Jamshed B. Bomanji, Narainder Gupta, Parveen Gulati, et al.

For additional articles in this collection, see http://perspectivesinmedicine.cshlp.org/cgi/collection/ 